\section{POS1011 PREDICTORS OF ENDOTHELIAL DYSFUNCTION IN ANKYLOSING SPONDYLITIS}

A. Syngle ${ }^{1}$, N. Garg ${ }^{2}$, I. Verma ${ }^{3}$, P. Krishan ${ }^{4} .{ }^{1}$ Healing Touch City Clinic, Chandigarh, \& 2. Fortis Multi-specialty Hospital, 1. Cardio Rheuma Division; Internal Medicine and Rheumatology, Chandigarh, India; ${ }^{2}$ Chitkara University Chitkara College of Pharmacy, Department of Pharmacy Practice, Patiala, India; ${ }^{3}$ MM College of Pharmacy, Maharishi Markandeshwar, Department of Pharmacy Practice, Mullana, Ambala, India; ${ }^{4}$ Punjabi University, Department of Pharmaceutical Sciences and Drug Research, Patiala, India

Background: Cardiovascular (CV) disease is the leading cause of death in Ankylosing Spondylitis (AS). Chronic systemic inflammation driven endothelial dysfunction leading to accelerated atherosclerosis results in premature mortality. Endothelial dysfunction is potentially treatable hence a therapeutic target. Predictive biomarkers for endothelial dysfunction would allow tailoring therapy to the individual.

Objectives: To assess the endothelial dysfunction in AS in context of markers of inflammation and oxidative stress in AS patients.

Methods: Sub group-analysis of our previous studies of $\mathrm{AS}^{1-3}$ was carried out and 80 AS patients were compared with 40 healthy controls matched for age and sex that were also part of these studies. ${ }^{2,3}$ Such analysis had so far not been performed in this cohort. Patients with traditional CV risk factors had been excluded in these studies. Flow-mediated dilatation (FMD), as a measure of endothelial function, was assessed by AngioDefender (Everist Health, Ann Arbor, MI). Inflammatory measures included: Bath Ankylosing Spondylitis Disease Activity Index (BASDAI) and Ankylosing Spondylitis Disease Activity Score (ASDAS) in AS. We also assayed markers of inflammation, including C-reactive protein (CRP), erythrocyte sedimentation rate (ESR), proinflammatory cytokines (interleukin [IL]-1, IL-6, and tumor necrosis factor [TNF]- $\alpha$ ), and endothelial dysfunction, including lipids and nitrite and marker of oxidative stress, TBARS.

Results: FMD was significantly lower in AS patients compared with controls $[(5.80 \pm 0.35 \%$ vs. $9.09 \pm 0.35 \%, p \leq 0.05)$ reduced by approximately $36 \%]$ whereas serum nitrite, TBARS, total cholesterol and LDL levels were significantly higher in AS compared with controls $(p \leq 0.05)$. Compared with controls, AS patients had significantly high BASDAI, ASDAS and increased concentrations of ESR, CRP, TNF- $\alpha$, and IL-6. In AS, FMD inversely correlated with ASDAS, CRP (Figure 1A), TNF- $\alpha$ (Figure 1B), nitrite (Figure 1C) and TBARS (Figure 1) and positively correlated with $\mathrm{HDL}(\mathrm{p} \leq 0.05)$

Conclusion: In AS, FMD was impaired, indicating endothelial dysfunction. ASDAS, CRP, TNF- $\alpha$, nitrite, and TBARS were independent predictors of FMD in AS. AS-related inflammatory mechanisms (TNF- $\alpha$, IL-6) and markers of vascular function and oxidative stress (CRP, nitrite and TBARS) may all be involved in the development of cardiovascular disease in AS and these predictors could serve as a novel therapeutic targets for preventing $\mathrm{CV}$ risk in AS.

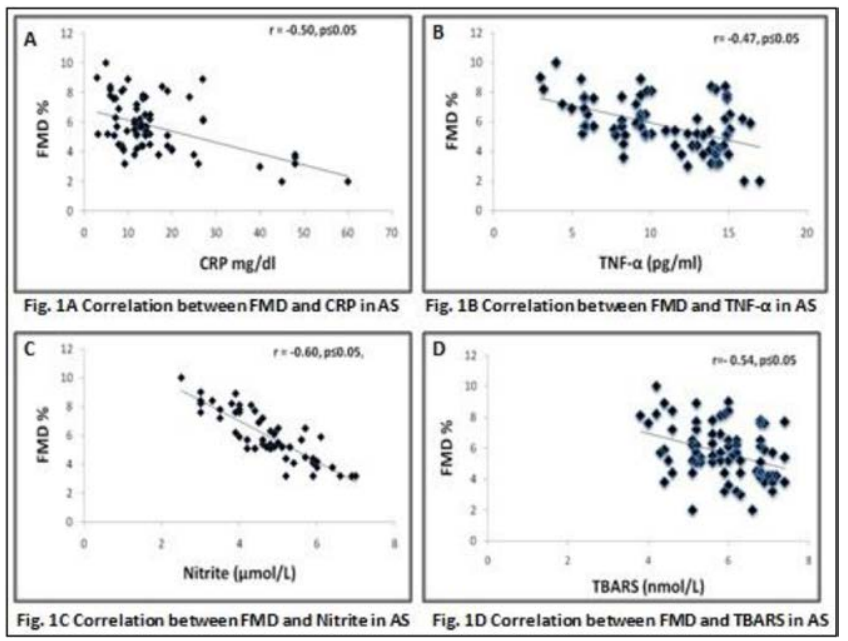

Figure 1. Correlation of FMD with CRP, TNF- $\alpha$, Nitrite and TBARS

\section{REFERENCES:}

[1] Garg N, Krishan P, Syngle A. Rosuvastatin improves endothelial dysfunction in ankylosing spondylitis. Clin Rheumatol. 2015;34:1065-1071.

[2] Verma I, Syngle A, Krishan P, Garg N. Endothelial Progenitor Cells as a Marker of Endothelial Dysfunction and Atherosclerosis in Ankylosing Spondylitis. International Journal of Angiology. 2017;26:36-42.

[3] Verma I, Krishan P, Syngle A. Predictors of Atherosclerosis in Ankylosing Spondylitis. Rheumatol Ther. 2015;2(2): 173-182.
Disclosure of Interests: None declared.

DOI: 10.1136/annrheumdis-2021-eular.3635

\section{POS1012 HOW IMPORTANT WOULD BE THE IMPACT OF SPONDYLOARTHRITIS ON MILITARY POPULATION'S WORKING LIFE?}

T. Mehmli ${ }^{1}$, R. Dhahri ${ }^{1}$, M. Slouma ${ }^{1}$, E. Hannech ${ }^{1}$, B. Louzir ${ }^{2}$, L. Metoui ${ }^{1}$, I. Gharsallah ${ }^{1} .{ }^{1}$ Military Hospital of Tunis, Rheumatology department, Tunis, Tunisia; ${ }^{2}$ Military Hospital of Tunis, Internal medecine department, Tunis, Tunisia

Background: Spondyloarthritis is a group of chronic inflammatory diseases involving axial and peripheral joints. It mainly affects young patients typically of working age. Therefore, its impact on work outcomes may be considerable particularly in military patients.

Objectives: The aim of this study was to evaluate the impact of spondyloarthritis on work ability and productivity in military patients, and to assess relationship between work productivity loss and disease activity.

Methods: Thirty Three patients diagnosed with spondyloarthritis in the militay hospital of Tunis were included in the study. Age, gender and C-reactive protein were recorded. Data related to duration of the disease, Ankylosing Spondylitis Disease Activity Score (ASDAS) and Bath Ankylosing Spondylitis Disease Activity Index (BASDAI) were also recorded. Employed patients completed Work Productivity and Activity Impairment (WPAI) questionnaire witch assesses four subscales: presenteism, absenteism, overall work impairemend and daily activity impairement in the 7 past days.

Results: Among the thirty three patients, $63 \%$ were men and $37 \%$ were women The average age was $43,7 \pm 13,5$. The average duration of disease was $8,5 \pm$ 7,75 years. Mean C-Reactive protein was $27,5 \pm 39,3$. Mean ASDAS and BAS DAl were $3,12 \pm 1,39$ and $4,26 \pm 1,78$ respectively. 22 patients $(66 \%)$ had an active disease and 11 (33\%)were in remission. $48,4 \%$ of patients were using NSAIDs, $48,4 \%$ were under DMARDs and $42 \%$ were under biologics ( 12 patients using TNF-alpha blockers and 2 patients were given IL-17 inhibitors). Among this patients, 27 were employed. Three patients $(11 \%)$ had a total work disability and were retired from work and two have been outplaced.

Employed patients worked an average of 35,6 $\pm 10,3$ hours per week and missed an average of $3,48 \pm 6,49$ hours per week. The mean rates of absenteeism presenteeism and work productivity loss were $8,8 \pm 16,9 \%, 48,4 \pm 19,9 \%$ and $48,6 \pm 19,7 \%$.

There was a statistically significant correlation between BASDAI and work missed hours $(p<0,05, r=0,48)$, absenteeism $(p<0,05, r=0,48)$, presenteeism $(p<0,01$, $r=0,669)$, work impairement $(p<0,01, r=0,669)$, activity impairement $(p<0,05$, $r=0,475)$ and work productivity loss $(p<0,05, r=0,475)$, as well as between ASDAS CRP and presenteeism $(p<0,05, r=0,593)$, work impairement $(p<0,05, r=0,593)$ activity impairement $(p<0,05, \quad r=0,460)$ and work productivity loss $(p<0,05$ $r=0,460)$. No relation was found between WPAI indexes and $C$-reactive protein.

Conclusion: This study demonstrates that spondyloarthritis has a major impact on military patients' work productivity with a significant correlation between WAP indexes and disease activity scores (ASDAS CRP and BASDAI). No relation was found with C-reactive protein.

Disclosure of Interests: None declared.

DOI: 10.1136/annrheumdis-2021-eular.3740

\section{POS1013 \\ LET'S TAKE A LOOK AT THE SYMPHYSIS PUBIC AREA IN SPONDYLARTHRITIS}

H. Hajii ${ }^{1}$, H. Ferjani ${ }^{1}$, K. Maatallah ${ }^{1}$, S. Miri ${ }^{1}$, C. Ines ${ }^{1}$, M. Yasmine ${ }^{1}$, D. Kaffel ${ }^{1}$, W. Hamdi ${ }^{1}{ }^{1}$ Kassab Institute, Tunis; Rheumatology, Tunis, Tunisia

Background: Symphysis pubic (SP) is the frequent site of enthesitis in spondylarthritis $(\mathrm{SpA})$. Radiological changes in SP appear later in the course of the disease. Underdiagnosed, its prevalence varies from $4 \%$ to $47 \%$ (1), depending on imaging modalities.

Objectives: This study aimed to evaluate the prevalence of SP involvement in patients with spondyloarthritis (SpA). We also focused on the relation between radiographical changes and clinical findings.

Methods: It was a cross-sectional study, including patients with SpA according to the Assessment of SpondyloArthritis International Society (ASAS) criteria. We collected the following data: age, gender, Bath Ankylosing Spondylitis Disease Activity Index (BASDAI), Ankylosing Spondylitis Disease Activity Score (ASDAS), and Bath Ankylosing Spondylitis Functional Index (BASFI).

Pelvic radiographs were examined by 2 experimented rheumatologists. Grading symphysial involvement was made as follow: scores ranged from 0-4 per reading: grade $0=$ normal; grade $1=$ subtle irregularity and/or subchondral sclerosis, grade 2 = clear erosions, $3=$ marked sclerosis, grade $4=$ ankylosis .

We divided our patients into two groups: G0 patients without SP changes and G1 patients with SP changes.

Results: One hundred and thirty-one patients were included, 84 were male, and 48 were female. The sex ratio M/F was 1.72 . The mean age was $41.32 \pm 12.42$ 